\title{
Implementação e avaliação de um vídeo educativo para famílias e pessoas com colostomia*
}

\author{
Implementation and evaluation of an educational video \\ for the families of people with colostomy
}

\author{
Implementación y evaluación de vídeo educativo \\ para familias y personas con colostomía
}

Daiane de Oliveira Stragliotto ${ }^{1}$, Nara Marilene Oliveira Girardon-Perlini', Bruna Vanessa Costa da Rosa', Angélica Dalmolin ${ }^{1}$, Elisabeta Albertina Nietsche ${ }^{1}$, Itagira Manfio Somavilla', Maria Elizete Nunes da Silva ${ }^{1}$

\begin{abstract}
RESUMO
Os vídeos educativos são estratégias de educação em saúde que podem contribuir para que as pessoas desenvolvam habilidades para o cuidado de estomias. Objetivou-se implementar e avaliar as repercussões de uma intervenção de enfermagem realizada por meio de um vídeo educativo para famílias de pessoas com colostomia decorrente de câncer. Trata-se de um estudo descritivo e de abordagem qualitativa. O cenário foi composto por dois hospitais do interior do Rio Grande do Sul. O estudo foi realizado com dados de 10 famílias, totalizando 24 participantes. A coleta dos dados ocorreu entre maio e agosto de 2015 e os resultados foram submetidos à análise temática. Como resultados, foram organizadas três categorias: "Colostomia": conhecimento prévio a intervenção; "Aprendi com o vídeo": repercussões após intervenção de enfermagem; "O vídeo é válido sim!": percepções das famílias em relação ao vídeo educativo. Concluiu-se que a intervenção de enfermagem por meio do vídeo educativo repercutiu positivamente nas famílias das pessoas com colostomia decorrente de câncer colorretal. O vídeo tem potencial para ajudar em relação à aprendizagem dos cuidados com a colostomia, aos aspectos emocionais e à comunicação entre os familiares, além de seu caráter esclarecedor, descrito pelas pessoas que o assistiram.
\end{abstract}

DESCRITORES: Estomia. Colostomia. Família. Educação em saúde. Tecnologia. Enfermagem. Estomaterapia.

\begin{abstract}
Educational videos are health education strategies that can help people develop ostomy care skills. The objective was to implement and evaluate the repercussion of a nursing intervention through an educational video to the families of people with colostomy by cancer. This is a study of descriptive and qualitative approach carried out at two hospitals in Rio Grande do Sul. The participants were 10 families, totaling 24 peoples. Data were collected between May and August 2015 and the results were submitted to thematic analysis. The results were organized into three categories: "Colostomy": knowledge prior to the intervention; "I learned from the video": repercussions after nursing intervention; "The video is valid, yes!": perceptions of families in relation to the educational video. It was concluded that the nursing intervention through educational video had a positive repercussion on the families of people with colostomy for colorectal cancer. The video has the potential to help in relation to learning colostomy care, the emotional aspects and the communication between family members, in addition to being perceived as enlightening to the people who watched it.
\end{abstract}

DESCRIPTORS: Ostomy. Colostomy. Family. Health Education. Technology. Nursing. Stomatherapy.

\footnotetext{
*Artigo oriundo da dissertação intitulada "Implementação e avaliação de um vídeo educativo para famílias de pessoas com colostomia", apresentada em 2016 ao Programa de Pós-Graduação em Enfermagem da Universidade Federal de Santa Maria, Rio Grande do Sul. Contou com o auxílio financeiro do Programa de Iniciação Científica para o Hospital Universitário de Santa Maria da Universidade Federal de Santa Maria.

${ }^{1}$ Universidade Federal de Santa Maria - Santa Maria (RS), Brasil.

Endereço para correspondência: Avenida Roraima, 1000 - Centro de Ciências da Saúde. Prédio 26, Sala 1339 - Camobi - CEP: $97105-900$ - Santa Maria (RS), Brasil - E-mail: nara.girardon@gmail.com

Artigo recebido em: 21/12/2016 - Aceito para publicação em: 06/08/2017
} 


\section{RESUMEN}

Los videos educativos son estrategias de educación para la salud que pueden ayudar a las personas a desarrollar habilidades de cuidado de ostomias. El objetivo era poner en práctica y evaluar las repercusiones de una intervención de enfermería realizada por un video educativo para las familias de las personas con colostomía derivada del cáncer. Se trata de un estudio de enfoque descriptivo y cualitativo. El escenario fue compuesto por dos hospitales en el Rio Grande do Sul. Participaron 10 familias, con un total de 24 participantes. La recolección de datos se llevó a cabo entre mayo y agosto de 2015 y los resultados fueron sometidos al análisis temático. Los resultados se organizaron en tres categorías: "Colostomía": conocimiento previo a la intervención; "Aprendí con el video": repercusiones después de la intervención de enfermería; "¡El vídeo es sí válido!'"': las percepciones de las familias en relación al video educativo. Se concluyó que la intervención de enfermería por medio del video educativo tuvo repercusión positiva en las familias de las personas con colostomía para el cáncer colorrectal. El vídeo tiene el potencial de ayudar en relación con el aprendizaje de los cuidados de colostomía, los aspectos emocionales y también en la comunicación entre los miembros de la familia, además de su carácter esclarecedor, descrito por las personas que lo asistieron.

DESCRIPTORES: Estomía. Colostomía. Familia. Educación en Salud. Tecnología. Enfermería. Estomaterapia.

\section{INTRODUÇÃO}

O diagnóstico de câncer colorretal e a necessidade da realização de uma colostomia provocam insegurança, além de medo da morte e das alterações no estilo de vida do indivíduo acometido. As restrições nas atividades diárias advindas do adoecimento, da cirurgia e de suas consequências fazem com que o ritmo de vida da pessoa fique atrelado ao funcionamento do estoma. Desse modo, a colostomia confere um tempo diferente ao cotidiano, exigindo que o paciente conviva com a experiência de aceitação e das limitações do seu novo eu ${ }^{1}$.

Mudanças ocorrem também para a família, que igualmente é afetada pelas situações decorrentes do adoecimento ${ }^{2}$. A família pode influenciar consideravelmente o modo como as enfermidades que venham a acometer um de seus membros serão gerenciadas, em virtude do papel significativo que exerce em relação à saúde e ao bem-estar de seus integrantes.

Entende-se família como um grupo de pessoas que são ligadas por vínculos consanguíneos ou afetivos, que participam da vida umas das outras ${ }^{3}$.

Assim, considerando que no contexto da realização da cirurgia para remoção de tumor o enfermeiro, como integrante da equipe de saúde, tem um papel mediador no sentido de preparar a pessoa e sua família para confecção do estoma e de capacitá-los para lidar com a nova situação ${ }^{4}$, a enfermagem tem o compromisso de incluir as famílias em seus cuidados de saúde ${ }^{3}$. Nesse sentido, o enfermeiro deve respeitar as ideias e os saberes de cada membro da família em relação às suas vivências acerca do processo saúde-doença ${ }^{3}$, potencializando suas habilidades, estimulando a autonomia e fortalecendo a rede social ${ }^{5}$.
Nessa perspectiva, percebe-se a necessidade de o enfermeiro instrumentalizar, por meio de atividades de educação em saúde, não só a pessoa colostomizada, mas também seus familiares, que, muitas vezes, serão os responsáveis pelo cuidado da colostomia. As intervenções de enfermagem, por meio de ações educativas, constituem-se em uma possibilidade de viabilizar condições para que as pessoas desenvolvam habilidades para o cuidado e o autocuidado. A intervenção de enfermagem pode ser entendida como uma ação ou resposta do enfermeiro, que inclui ações terapêuticas na relação enfermeiro-paciente, visando influenciar no comportamento do indivíduo, da família ou da comunidade pela qual é responsável ${ }^{6}$.

O uso de vídeos educativos pode constituir-se em uma estratégia educativa que proporciona ao indivíduo e à sua família a construção de saberes relacionados ao cuidado com a estomia. Entende-se o vídeo como uma tecnologia que pode ser aplicada para a resolução de um problema. Não se pode banalizar a concepção de tecnologia, ou seja, compreendê-la apenas como um equipamento, uma mercadoria, e vê-la de forma simplista e sem consideração. A tecnologia não tem seu conceito restrito à informatização, à robótica e à cibernética. Para a enfermagem, a tecnologia consiste em instrumentos e conhecimentos interligados, os quais são construídos, desconstruídos e novamente reconstruídos ao longo dos tempos pelas pessoas ${ }^{7}$.

Em uma revisão integrativa de estudos sobre intervenções de saúde com famílias que vivenciam o adoecimento por câncer, identificou-se a utilização de recursos audiovisuais como estratégia para disponibilizar informações e 
potencializar o cuidado eficaz e a qualidade de vida, tanto para a família quanto para as pessoas portadoras de neoplasias ${ }^{8}$.

Nesse sentido, foi desenvolvido e validado com experts um vídeo especialmente voltado para famílias de pessoas que realizaram colostomia, com o objetivo de orientar quanto ao manejo do estoma, bem como apresentar depoimentos encorajadores para o enfrentamento da nova etapa da vida9.

Diante disso, o objetivo geral do estudo foi implementar e avaliar as repercussões de uma intervenção de enfermagem realizada por meio de um vídeo educativo para famílias de pessoas portadoras de colostomia por câncer. Já os objetivos específicos consistiram em

- identificar o conhecimento prévio à intervenção relacionado à colostomia e aos cuidados necessários;

- identificar o conhecimento posterior à intervenção relacionado à colostomia e aos cuidados necessários;

- avaliar as repercussões da intervenção de enfermagem realizada por meio do vídeo educativo;

- conhecer as percepções das famílias sobre o vídeo utilizado na intervenção de enfermagem.

\section{MÉTODOS}

Tratou-se de uma pesquisa de intervenção sustentada pela abordagem qualitativa do tipo exploratória, descritiva e transversal. O cenário do estudo compreendeu dois hospitais da Região Sul do Brasil, em que participaram dez famílias de pessoas que apresentavam colostomia resultante de câncer colorretal. Vale ressaltar que, ao mencionar o termo família, refere-se à unidade familiar que inclui a pessoa doente e os demais membros do grupo por ele considerados. Assim, destaca-se que o número de participantes da pesquisa foi de 24 pessoas. A coleta dos dados foi realizada de maio a agosto de 2015 , sendo convidadas todas as famílias de pessoas que haviam realizado cirurgia de colostomia decorrente de câncer nesse período.

A coleta dos dados ocorreu em duas etapas, as quais foram realizadas após a cirurgia. Na primeira etapa, foi realizada uma entrevista com as famílias durante a internação, com o objetivo de identificar o conhecimento prévio em relação à colostomia e seus cuidados. Após a entrevista, os participantes foram convidados a assistir ao vídeo educativo. $\mathrm{O}$ vídeo, com tempo de duração de 8 minutos e 35 segundos, constituiu-se de cenas de alguns cuidados básicos com a bolsa e o estoma e depoimentos de uma pessoa com colostomia e seu familiar. Foi disponibilizada uma cópia do vídeo em DVD para que os participantes pudessem assisti-lo novamente, caso desejassem, ou compartilhar com outros familiares.

A segunda etapa da coleta de dados foi realizada até 30 dias após a alta hospitalar, no retorno para revisão cirúrgica, por meio de entrevista semiestruturada com as pessoas que assistiram ao vídeo educativo. Essa fase teve o intuito de conhecer as repercussões e as percepções quanto ao vídeo educativo.

Foram definidos como critérios de inclusão na primeira etapa: ter, no mínimo, duas pessoas da família para assistir ao vídeo no momento da intervenção, podendo uma ser o próprio paciente e a(s) outra(s) ser(em) considerada(s) membro da família, ser maior de 18 anos, o que confere idade legal para decidir pela participação no estudo, e apresentar condições físicas e cognitivas (capacidade de compreensão e de fala, ausência de dor ou de outros desconfortos). Como critério de exclusão definiu-se como parâmetro indivíduos com colostomias de origem não neoplásica.

A segunda etapa considerou os mesmos critérios da anterior e a necessidade de que os participantes tivessem assistido ao vídeo educativo. O recorte temporal estabelecido observou a implementação de cuidados com a colostomia no domicílio.

Os dados coletados foram submetidos à análise temática, tendo como base a proposta operativa ${ }^{10}$. Para isso, inicialmente, realizou-se a ordenação dos dados, que compreendeu a transcrição das entrevistas, a releitura e a organização do material. Nessa fase, procedeu-se à realização do mapeamento dos resultados obtidos e à leitura superficial do material produzido. A classificação dos dados deu-se após leituras exaustivas e atentas com anotações das primeiras impressões de acordo com o objetivo proposto. Os temas que configuraram as categorias foram elaborados mediante o agrupamento das partes semelhantes que estabeleciam conexões de sentidos entre si. Para organização dessa etapa, utilizou-se como estratégia o recorte e a cromatografia. $\mathrm{Na}$ análise final, buscou-se a compreensão e a interpretação dos dados com base na articulação entre estes e a literatura de cotejamento.

Durante a realização da pesquisa, os direitos dos participantes foram preservados, observando-se as orientações da Resolução no 466, de 12 de dezembro de 2012, do Conselho Nacional de Saúde, que trata das Diretrizes e Normas Regulamentadoras de Pesquisa Envolvendo Seres Humanos $^{11}$. O projeto foi analisado por Comitê de Ética em Pesquisa e aprovado conforme Parecer no 1077.729. Todas as pessoas assinaram o Termo de Consentimento 
Livre e Esclarecido. Para manter o anonimato, os participantes foram identificados por códigos para cada família (F1, F2, F3, sucessivamente), assim como para cada entrevistado (E1, E2, E3, sucessivamente), por exemplo: F1 - E1 (família 1 - entrevistado 1).

\section{RESULTADOS}

Dos participantes do estudo, 10 eram pessoas com colostomia e, 14, familiares. Ao analisar separadamente os indivíduos com colostomia, pôde-se evidenciar que houve predomínio de pessoas do sexo masculino (6), na faixa etária de 50 a 69 anos de idade (6). Em relação aos familiares, identificou-se que a maioria era do sexo feminino (13), na faixa etária de 40 a 60 anos de idade (10). No processo analítico foram elaboradas três categorias temáticas.

\section{Categoria I - "Colostomia": conhecimento prévio à intervenção}

Os dados da pesquisa revelam que as famílias tinham pouco ou nenhum conhecimento sobre a colostomia e seus cuidados antes de participarem da intervenção de enfermagem. As famílias relataram estar passando por um momento delicado, em que tudo era novo, referindo não conhecer e não ter tido contato prévio com uma pessoa que tivesse colostomia. A realização da cirurgia e a confecção do estoma colocam a família e o paciente em um contexto diferente ao vivido anteriormente, trazendo desafios e necessidades de aprender a lidar com algo que exige um novo modo de viver.

Constatou-se, por meio das falas, que, mesmo não tendo contato ou vivência com uma colostomia, os participantes expressavam o desejo de instruir-se em relação aos cuidados, porém como uma necessidade para depois da alta hospitalar.

Para nós tudo é novidade.É só o que eu vejo fazer aqui.(F7,E1)

Sabia que ele iria ter que usar, mas não sabia como a gente iria lidar. Vamos ter que aprender. Eu nunca lidei com ninguém assim, nunca vi. (F3, E2)

Em relação aos cuidados com a bolsa de colostomia, algumas famílias referem não ter conhecimento sobre como manuseá-la. Identifica-se, nas falas, o desconhecimento acerca de aspectos relacionados aos desvelos necessários com esse recipiente, como a técnica adequada para realizar a troca e qual a posição correta para colar no abdome.

Como trocar a bolsa? Não sei nada. Eu nunca tive contato. Eu espero sair daqui sabendo como trocar. Porque eu não sei se eu vou ter coragem de trocar. (F5, E1)

A posição dela. Eu não sei por que colocaram assim. Ela pode ser colocada em várias posições? (F6, E1)

A execução dos procedimentos gera sentimentos de medo e insegurança, tanto para enfrentar e se adaptar ao novo contexto quanto para prestar os cuidados necessários em relação à colostomia. Por outro lado, as familias demonstram estar cientes de que a cirurgia se faz necessária para a remoção do tumor, assim como entendem a respeito da consequente realização de uma colostomia. Fica expresso nas falas que as famílias sabiam que a colostomia era decorrente do diagnóstico de câncer colorretal e da necessidade de ressecção de parte do intestino.

O câncer em mim é no reto. Então tem que desviar, não pode deixar passar por ali porque pode raspar. É isso aí o problema. Tem que desviar. (F4, E1)

Foi retirado o tumor do intestino, fizeram um desvio, que ela irá ficar uns seis meses com aquela bolsinha. (F7, E2)

Outras familias, no entanto, referem algum conhecimento em relação à colostomia e ao manejo com o estoma. Entre esses, destacam os cuidados com a pele, a limpeza da bolsa de colostomia e o seu tempo de durabilidade. Cabe ressaltar que essas informações foram adquiridas no pós-operatório, por meio da observação dos cuidados que os profissionais da saúde prestavam ao indivíduo com colostomia.

Não pode trocar muito seguido para não machucar a pele. Percebemos que precisa recortar o tamanho da bolsa, não deixar muito grande para o ácido não pegar na pele. (F4, E2)

Eu tiro as secreções, para não ficar pesado, que machuca, força a pele. Eles me deram um soro, aí eu tiro e boto soro ali e dou uma... com a mão assim, sabe (movimento de balançar), para tirar aquelas...(fezes) e aí fecho de novo.Tranquilo! (F7, E2)

Vale ressaltar que o fato de ter familiaridade com os cuidados prestados a uma pessoa com estoma intestinal confere 
conhecimento e habilidades para lidar com a colostomia, favorecendo segurança e confiança. Nota-se que o enfrentamento desse processo, quando vivido anteriormente, torna-se menos complexo. A pessoa que já viveu essa experiência percebe a colostomia como uma maneira de proporcionar qualidade de vida e uma alternativa para seguir em frente.

Porque eu já cuidei várias vezes, então é normal, sabe? Na verdade, é qualidade de vida. Ainda bem que tem essa opção... (F8, E2)

Diante da situação que se apresenta, evidencia-se que as famílias necessitam instrumentalizar-se para potencializar o conhecimento prévio e as habilidades já adquiridas, direcionando-os para o processo de aceitação da nova condição, de conviver com o estoma e com os cuidados que ele demanda, favorecendo o retorno da independência e da autonomia.

\section{Categoria II - "Aprendi com o vídeo": repercussões após a intervenção de enfermagem}

Considerando que o objetivo do vídeo educativo é promover a autonomia e o empoderamento do indivíduo com colostomia e de sua família em relação aos cuidados, após terem assistido à tecnologia educativa, buscou-se identificar como as pessoas perceberam o conteúdo assistido no contexto do cuidado.

Os participantes do estudo mencionaram que, por meio do vídeo, sentiram-se mais instrumentalizados para realizar a troca da bolsa de colostomia e tomar os cuidados necessários com o estoma nesse procedimento, ou seja, a importância do recorte adequado da bolsa ao tamanho do estoma, para evitar possíveis lesões na pele que o circunda. Em relação à durabilidade das bolsas, demonstram ter aprendido sobre o aspecto que elas apresentam quando devem ser substituídas.

Esvaziar eu aprendi com o vídeo. Eu tiro e coloco no vaso aqueles resíduos, faço de tudo para não encostar no vaso e limpo, bem limpinho. Cortar conforme o tamanho, não muito apertada para evitar machucar. Aprendi que só troca quando começa a apresentar problemas, descolar ou coisa parecida, dar vazamento. Quando tomar banho pode lavar direto. (F5, E1)

Fiz como no vídeo: eu usei luva. A gente recortou, tirou os excessos. Se fica uma pontinha, machuca! Só cola depois que limpou, porque tem que fazer a higiene de tudo e daí colar de novo a outra. (F3, E2)
Elas explicaram, mas não ia conseguir fazer sem ver como era. Aí eu lembrei do vídeo que mostrou como fazia.(F9, E2)

Outro aspecto refere-se à higienização da bolsa em situações fora do domicílio. A tecnologia educativa possibilitou às famílias a aprendizagem de maneira a facilitar quando o cuidado deve ser feito fora de casa, evitando constrangimentos na hora de realizar o esvaziamento da bolsa.

Que nem ela explicou ali no vídeo. Tem que levar um kit de limpeza, porque fica o cheiro no banheiro de onde a gente sai. Geralmente suja na volta do vaso... Então, a gente prepara um kit, com uma luva para limpar o vaso, com desinfetante para passar no banheiro... Tudo isso a gente aprendeu ali. (F5, E2)

Para sair, o que tem que levar? Isso eu achei que tem que saber! Agora eu sei, porque eu olhei. Acho que é bem mais fácil agora. A gente fica mais forte para lidar. (F6, E3)

Percebe-se que o vídeo educativo fortaleceu e encorajou os participantes a saírem de suas casas, por orientar como lidar com a colostomia e as possíveis adversidades fora de seus lares. Desse modo, identifica-se que a tecnologia educativa, de algum modo, contribui para desenvolver a autonomia para o cuidado e, por consequência, a segurança para viver com essa mudança corporal e de vida.

As manifestações das famílias indicam que o vídeo os ajudou a ver a colostomia com "outros olhos"; que o conteúdo apresentado contribuiu para deixá-los mais tranquilos e mais confiantes. Ao mencionar os depoimentos que compõem o vídeo, referem-se a ele como confortador, porque expressa, de outra forma, a realidade.

A partir dos depoimentos do vídeo, os participantes puderam ver que há outras pessoas que já enfrentaram esse mesmo processo. Essa constatação parece ter influenciado os entrevistados a não se perceberem únicos, vivendo uma realidade que não é somente deles. Saber que há mais pessoas que já passaram por essa experiência, ver a imagem de alguém com estoma e falando sobre como convive com a colostomia, que se adaptou e hoje vive bem, confere normalidade à situação.

Ajudou não só a fazer a limpeza, mas também psicologicamente, que a minha preocupação era de como eu iria usar essa bolsinha e como eu iria para algum lugar assim. No depoimento daquela senhora dá para ter uma vida normal, tranquila... sem problema nenhum aquilo! Era essa a minha preocupação! (F3, E1) 
Mas para nós, que nem eu te disse, a tua autoestima levanta! Ver uma pessoa falando! Tu sabe que é um vídeo, mas é uma verdade! Me incentivou muito, porque a gente fica uma pilha de nervos, não tem quem não fique, não tem, não existe. Dá vontade de se encerrar num quarto e não sair mais. A mulher que deu a entrevista ali no vídeo te bota pra cima! Hoje eu saio e caminho lá na vila, graças a Deus. Me tranquilizou muito. (F5, E1)

O âmbito familiar foi outro contexto em que o vídeo educativo suscitou repercussões. Os depoimentos permitiram identificar que as famílias se reuniram para assistir ao vídeo novamente em casa, o que pode ter facilitado e auxiliado a comunicação entre eles. Pôde-se perceber que houve uma aproximação entre os membros da família, envolvendo-os no cuidado e mostrando a importância da união nessa experiência.

O guri do vídeo falou, acho que era o sobrinho, que estava toda a família cuidando da paciente. A mesma coisa que nós! (F9, E2)

Nós olhamos em casa também, com as crianças. A família.... As crianças.... É um grude! E com essa doença a gente se agarra mais, se une mais. (F5, E1)

Constata-se que o vídeo educativo, por apresentar imagens e sons, facilita tanto o aprendizado das famílias quanto a sua memorização. Fica evidente que ao realizar o cuidado os participantes se lembraram das imagens do vídeo, o que os ajudou a executar a troca da bolsa e realizar os cuidados que a estomia demanda. Referem, também, que ao olhar o vídeo conseguiram entender melhor o que tinham de fazer para pôr em prática o cuidado com a colostomia, o que os deixa mais independentes e confiantes.

\section{Categoria III - “O vídeo é válido sim!": percepções das famílias em relação ao vídeo educativo}

Percebe-se a utilização do vídeo educativo como uma estratégia válida para orientar as famílias no cuidado e no manejo da colostomia. Ele é percebido como esclarecedor, uma vez que, por meio de imagens, orienta quanto à limpeza e quanto aos cuidados que a bolsa demanda, auxiliando também na elucidação de dúvidas que as famílias apresentam. Ainda, por meio dos depoimentos, percebe-se que o vídeo serviu como uma ferramenta que proporcionou, de certo modo, tranquilidade, pois conseguiu retratar de forma eficaz a nova realidade de vida do paciente, ajudando a família a ver esse ciclo de uma forma mais compatível com o antigo cotidiano.

É, ajudou muito! A nós ele ajudou muito! Aquele vídeo foi importante para nós, principalmente porque aquela bolsa é um troço estranho no corpo. Como é que eu vou te dizer... A gente aprendeu e viu que o troço não é tudo aquilo! Me ajudou muito (F5, E1)

O vídeo em si é muito importante, é muito bom. Foi bem esclarecedor, não ficou nada de dúvida. $\mathrm{O}$ vídeo esclarece muito, esclarece muitas dúvidas que a gente tem. De limpeza, de tudo, como é que faz. Até os parentes ali ajudando.... Olha, o vídeo achei muito importante. $\mathrm{O}$ que foi colocado ali foi uma educação. (F2, E1)

Por mais que tenham entendido a tecnologia educativa como positiva, os participantes consideraram que o vídeo poderia apresentar algumas modificações, caso fosse reeditado. Considerou-se como sugestão apresentar uma pessoa com um estoma em fase inicial, logo após a cirurgia, estando assim mais próxima da realidade das famílias entrevistadas. Sugeriu-se a participação de um "ator" mais jovem, como um fator de motivação, uma vez que essa realidade não é exclusiva de pessoas com idade avançada.

O dela já está cicatrizado, né? Não digo mudar, digo acrescentar... Colocar mais no início, depois da cirurgia.(F3, E1)

Uma pessoa mais nova, de repente, também poderia fazer o vídeo. Mais jovem, né? Porque daí já é mais um incentivo. A pessoa é uma senhora mais de idade. (F5, E2)

Outro aspecto apresentado refere-se à percepção do vídeo como idealizador, omitindo as dificuldades presentes nessa experiência e supervalorizando a superação. Entretanto, ponderam que a opção por não apresentar as dificuldades pode ser benéfica, pois a realidade, por si, revela os desafios do conviver com a colostomia e com o adoecimento. Assim, incluir as dificuldades poderia suscitar apreensão a quem fosse assistir ao vídeo, estimulando sentimentos de insegurança e medo. 
O vídeo mostra só a facilidade. Não mostra trauma nenhum. Mostra só a parte boa, mais fácil, embora seja difícil. Não é fácil a convivência com essa situação! Mas eu não acrescentaria isso, porque senão seria muito ruim. Tu já ia ficar mais temeroso para a realidade. Assim não. Na prática tu aprendes e aí se torna tranquilo! (F4, E3)

Considera-se que a tecnologia desenvolvida foi importante para as famílias, uma vez que teve um papel educativo e colaborou para o desenvolvimento de habilidades que facilitaram a autonomia. $O$ vídeo educativo também contribuiu para que mudassem a visão que tinham sobre o que é ser uma pessoa com colostomia, conseguindo conviver com a nova condição e aceitar que é possível ter uma vida normal.

\section{DISCUSSÃO}

Pelos resultados obtidos, pôde-se constatar que muitas famílias desconhecem os aspectos relacionados ao estoma, à colostomia e aos cuidados por ocasião da cirurgia, mesmo já estando no pós-operatório. Alguns estudos têm discutido acerca do momento em que as orientações a pacientes e familiares têm sido realizadas e o quanto elas conseguem ser efetivas como processo educativo e fonte de aprendizagem, pois, muitas vezes, as pessoas implicadas estão preocupadas com outras demandas e não conseguem absorver o que é transmitido ${ }^{12}$.

Um estudo que buscou descrever o uso de uma tecnologia educativa para a prática do cuidado de enfermagem na área materno-infantil identificou que as mães desconheciam o tratamento utilizado e, em consequência, vinha a negação dele e uma impressão distorcida sobre o mesmo ${ }^{13}$. Pode-se projetar esse fato para o presente estudo, uma vez que nesta pesquisa os participantes que informaram desconhecimento em relação à colostomia e ao seu manuseio manifestaram sentimentos de medo e insegurança diante da necessidade de prestar os cuidados que a estomia demanda.

Embora tendo referido pouco ou nenhum conhecimento em relação aos cuidados com o estoma, as famílias demonstraram reconhecer que o familiar estava se submetendo a um processo cirúrgico para retirada de um tumor. Situação similar foi encontrada em pesquisa que identificou que, quando indagados sobre o que sabiam em relação aos seus estomas, os participantes referiam conhecimentos precários, limitando-se ao procedimento cirúrgico ${ }^{14}$.
O conhecimento é o ato ou efeito de conhecer, de ter competência ou sabedoria em relação a um assunto ou a um fato ${ }^{15}$. O ato de conhecer, ou seja, de inteirar-se traz empoderamento e faz com que os sujeitos busquem tornar-se autônomos e independentes diante de suas necessidades. Neste estudo, as famílias, após participarem da intervenção de enfermagem por meio do vídeo educativo, puderam ampliar sua compreensão em relação aos cuidados básicos com a estomia, o que contribuiu para que elas pudessem desenvolver algumas habilidades e, consequentemente, se sentissem mais seguras para manusear a bolsa de colostomia, em um primeiro momento. Nessa perspectiva, estudo que implementou um plano de ensino para autoirrigação da colostomia concluiu que a estratégia educativa utilizada possibilitou conhecimento aos participantes, pois eles aprenderam a utilizar essa técnica, o que permitiu uma melhora na qualidade de vida ${ }^{16}$.

Pôde-se apreender que a intervenção de enfermagem por meio do vídeo educativo apresenta-se como um recurso que contribui para a aprendizagem de quem o assiste. Essa intervenção de enfermagem, especificamente, desempenha um papel educativo e reflexivo que incentiva a autonomia e fortalece para a reinserção social. A educação em saúde é uma prática social que visa contribuir para a formação de um pensamento crítico nas pessoas para que, por meio disso, consigam transformar a realidade em que vivem e solucionar os seus problemas ${ }^{17}$.

A implementação do vídeo educativo repercutiu positivamente no enfrentamento da doença, na autoestima, nos cuidados com a colostomia e na família. Em uma pesquisa que, a partir de uma tecnologia educativa, analisou as mudanças ocorridas no estilo de vida de trabalhadores na prevenção de fatores de risco da hipertensão arterial sistêmica, constatou-se que a estratégia utilizada proporcionou mudanças não só nessa forma de viver, mas também motivação para mantê-las e inserir outras que fossem necessárias $^{18}$. Esse resultado reforça as evidências encontradas neste estudo, corroborando para reafirmar que a repercussão da tecnologia educativa por meio do vídeo pode ser útil para a promoção da saúde, a instrumentalização do cuidado e a melhoria da qualidade de vida, tanto do paciente quanto de sua família.

Em relação à repercussão que o vídeo educativo proporcionou para a melhora da autoestima, principalmente da pessoa portadora do estoma, destacam-se os resultados obtidos em estudo que também utilizou uma 
tecnologia educativa, por meio de um plano de ensino, e identificou redução de problemas emocionais, sociais e físicos de seus participantes. Os autores ainda enfatizam que a participação dos familiares foi fundamental, uma vez que o apoio da família traz incentivo e reduz a insegurança e a ansiedade ${ }^{16}$.

No contexto familiar, os resultados apontam que a tecnologia educativa se mostrou eficaz também para promover a integração familiar, pois o ato de assistir ao vídeo em casa, possibilitando a participação de outros membros da família, favoreceu a união nesse momento, estimulando a comunicação entre os familiares. $\mathrm{O}$ vídeo, nessa perspectiva, apresenta potencial para ser um dispositivo promotor da comunicação no ambiente familiar. Assim, considerando que a confecção do estoma e o diagnóstico de câncer produzem uma profunda repercussão na vida de todos da família, estabelecer um diálogo aberto ${ }^{6}$ sobre a situação poderá ajudar na mobilização de forças para o enfrentamento da situação e a tomada de decisões.

$\mathrm{O}$ uso de ferramentas tecnológicas tem se apresentado na literatura como um importante recurso para apoio às famílias cuidadoras em diferentes contextos e como forma de qualificar o cuidado prestado. Nesse sentido, estudo que buscou descrever a efetividade de um vídeo para os cuidadores familiares de pessoas com doenças crônicas destaca, contudo, que o uso dessa tecnologia requer, muitas vezes, um processo de acompanhamento para verificar a apropriação dos conteúdos e a aquisição de habilidades ${ }^{19}$.

No fazer da enfermagem, a utilização de tecnologias aperfeiçoa a prática do cuidado, tanto nas atividades assistenciais quanto nas relações interpessoais estabelecidas entre os sujeitos envolvidos no processo de cuidar ${ }^{20}$. O uso de recursos audiovisuais para ações de educação em saúde torna esse processo mais dinâmico e interativo, pois exige imaginação e criatividade por parte dos enfermeiros e permite a identificação de quem o assiste com as situações vivenciadas ${ }^{19}$. O emprego das tecnologias ocorre de forma variada no cotidiano assistencial, podendo ser influenciadas de acordo com os significados que são atribuídos a elas na sua utilização como ferramenta do cuidado ${ }^{20}$. O desenvolvimento de recursos e de avanços tecnológicos que trabalhem em relação às doenças é necessário para que um número maior de pessoas possa ter acesso às informações ${ }^{19,21}$.

Nesse contexto, destaca-se a importância de estudos nessa área, para que o enfermeiro possa desenvolver estratégias de educação em saúde com o objetivo de orientar e propor formas de adaptação diante de possíveis dificuldades, minimizando, então, potenciais riscos à saúde ${ }^{22}$. Dessa forma, percebe-se a importância de inclusão de materiais educativos validados e avaliados na prática clínica, pois esses servem como um complemento das orientações realizadas pelos enfermeiros e demais profissionais da saúde, servindo como suporte de orientação e esclarecimento, contribuindo, assim, para a promoção da saúde do paciente ${ }^{23}$.

\section{CONCLUSÃO}

Pode-se afirmar que o objetivo de implementar e avaliar as repercussões de uma intervenção de enfermagem, realizada por meio de um vídeo educativo para famílias de pessoas portadoras de colostomia por câncer, foi alcançado. A estratégia de utilizar o vídeo educativo no pós-operatório, antes da alta hospitalar, foi considerada válida pelos participantes do estudo, mostrando-se esclarecedora e de aplicabilidade prática nesse contexto.

O vídeo tem potencial para ajudar em relação à aprendizagem dos cuidados com a colostomia, aos aspectos emocionais e também na comunicação entre os familiares. Contudo, sugere-se a realização de possíveis readaptações em estudos posteriores desenvolvidos nesse contexto, acrescentando-se aspectos relativos às particularidades inerentes, como, por exemplo, os tipos de estomas intestinais e o processo de evolução.

Como limitação da pesquisa destaca-se a opção metodológica utilizada no estudo, que não considerou as possíveis estratégias de orientações utilizadas pelos enfermeiros do campo hospitalar no preparo para a alta. Nesse sentido, entende-se que a realização de estudos com outras perspectivas metodológicas possa contribuir para avaliar a validade do vídeo utilizado.

Conclui-se que o vídeo educativo utilizado nesta pesquisa é válido para ilustrar e complementar as orientações de enfermagem às famílias que vivenciam situações de um familiar com colostomia decorrente de câncer. Por ser um recurso simples, de baixo custo, fácil implementação e compreensão, não necessita, necessariamente, da presença de um profissional para explicá-lo. Considera-se que sua utilização na prática clínica é aconselhável por apresentar benefícios para as pessoas que assistirem ao vídeo. 


\section{REFERÊNCIAS}

1. Ribeiro CO, Muniz RM, Furtado SMSR, Viegas AC, Amaral DED. Descobrindo o mundo estomizado: vivência das pessoas com o dispositivo. Rev Estima [Internet]. 2015 [citado em 1 jun. 2016];13(1). Disponível em: http://www.revistaestima. com.br/index.php/estima/article/view/100

2. Salci MA, Marcon SS. A convivência com o fantasma do câncer. Rev Gaúcha Enferm [Internet]. 2010 [citado em 18 jun. 2016];31(1):18-25. Disponível em: http:// www.scielo.br/scielo.php?script=sci_arttext\&pid =S1983-14472010000100003

3. Wright LM, Leahey M. Enfermeiras e famílias: guia para avaliação e intervenção na família. 5ª ed. São Paulo: Roca; 2012.

4. Sousa CF, Brito DC, Branco MZPC. Depois da colostomia... vivências das pessoas portadoras. Enfermagem em Foco [Internet]. 2012 [citado em 13 jun. 2016];3(1):125. Disponível em: http://revista.cofen.gov.br/index.php/ enfermagem/article/viewFile/213/134

5. Mota MS, Gomes GC, Petuco VM. Repercussions in the living process of people with stomas. Texto Contexto Enferm [Internet]. 2016 [citado em 25 jun. 2016]; 25(1). Disponível em: http://www.scielo.br/scielo.php?script=sci_ arttext\&pid=S0104-07072016000100317\&lng=pt\&nrm=iso

6. Wright $L M$, Watson $W L$, Bell JM. The family nursing unit: a unique integration of research, education and clinical practice. In: Bell JM, Watson WL, Wright LM, editors. The cutting edge of family nursing. Calgary, Alberta, Canada: Family Nursing Unit Publications; 1990.p. 95-109.

7. Nietsche EA, Teixeira E, Medeiros HP. Tecnologias cuidativoeducacionais: uma possibilidade para o empoderamento do(a) enfermeiro(a). Porto Alegre: Moriá; 2014.

8. Stamm B, Rosa BVC, Begnini D, Girardon-Perlini NMO. Intervenções de saúde com famílias que vivenciam o adoecimento por câncer: revisão integrativa. Rev Enferm UFPE [Internet]. 2014 [citado em 24 jun. 2016];8(Suppl. 3):4139-49. Disponível em: https://periodicos.ufpe.br/ revistas/revistaenfermagem/article/download/10153/10670

9. Rosa BVC. Desenvolvimento e validação de um vídeo educativo para famílias de pessoas com colostomia por câncer [dissertação]. Santa Maria: Universidade Federal de Santa Maria; 2015.

10. Minayo MCS. O desafio do conhecimento: pesquisa qualitativa em saúde. 14ª ed. São Paulo: Hucitec; 2014.

11. Brasil. Resolução n 466, de 12 de dezembro de 2012. Resolve aprovar as seguintes diretrizes e normas regulamentadoras de pesquisa envolvendo seres humanos. Diário Oficial da República Federativa do Brasil [Internet]. 13 jun. 2013 [citado em 25 jun. 2016]. Disponível em: http:// conselho.saude.gov.br/resolucoes/2012/Reso466.pdf

12. Bezerra IM. Assistência de enfermagem ao estomizado intestinal: revisão integrativa da literatura [dissertação]. Ribeirão Preto: Escola de Enfermagem de Ribeirão Preto, Universidade de São Paulo; 2007.
13. Campos ACS, Cardoso MVLML. Tecnologia educativa para a prática do cuidado de enfermagem com mães de neonatos sob fototerapia. Texto Contexto Enferm [Internet]. 2008 [citado em 10 nov. 2015];17(1):36-44. Disponível em: http:// www.scielo.br/pdf/tce/v17n1/04.pdf

14. Castro AB, Benício CDAV, Carvalho DC, Monte NF, Luz MHBA. Conhecimentos e práticas de pessoas estomizadas: um subsídio para o cuidar em enfermagem. Rev Estima [Internet]. 2014 [citado em 11 jan. 2016];12(4):21-8. Disponível em: http:// www.revistaestima.com.br/index.php/estima/article/view/98

15. Dicionário Aurélio de Português Online. Significado de Cuidado [Internet]. 2008 [citado em 11 jan. 2016]. Disponível em: http://www.dicionariodoaurelio.com/cuidado

16. Costa IG, Maruyama SAT. Implementação e avaliação de um plano de ensino para a autoirrigação de colostomia: estudo de caso. Rev Latino-Am Enferm [Internet]. 2004 [citado em 11 jun. 2016];12(3):557-63. Disponível em: http://www.scielo.br/scielo. php?script=sci_arttext\&pid=S0104-11692004000300015

17. Brasil. Fundação Nacional de Saúde. Diretrizes de educação em saúde visando à promoção da saúde: documento base documento I. Brasília: Funasa; 2007.

18. Santos ZMSA, Lima HP. Tecnologia educativa em saúde na prevenção da hipertensão arterial em trabalhadores: análise das mudanças no estilo de vida. Texto Contexto Enferm [Internet]. 2008 [citado em 12 jun. 2016];17(1):90-7. Disponível em: http://www.scielo.br/pdf/tce/v17n1/10.pdf

19. MartínezMVR,SilvaSLC. Elvideocomosoportesocialacuidadores de personas con enfermedad crónica, Girardot 2010. Av Enferm [Internet]. 2015 [citado em 4 jan. 2016];33(2):199-208. Disponível em: http://www.scielo.org.co/scielo.php?script=sci_ arttext\&pid=S0121-45002015000200002

20. Nietsche EA, Lima MGR, Rodrigues MGS, Teixeira JA, Oliveira BNB, Motta CA, et al. Tecnologias inovadoras do cuidado em enfermagem. Rev Enferm UFSM. Santa Maria, [Internet]. 2012 [citado em 25 jun. 2016];2(1):182-9. Disponível em: http://cascavel.ufsm.br/revistas/ojs-2.2.2/index.php/reufsm/ article/view/3591/3144

21. Moreira CBM, Bernardo EBR, Catunda HLO, Aquino OS, Santos MCL, Fernandes AFC. Construção de um vídeo educativo sobre detecção precoce do câncer de mama. Rev Bras. Cancerol [Internet]. 2013 [citado em 11 jun. 2016];59(3):401-7. Disponível em: http://www1.inca.gov.br/ rbc/n_59/v03/pdf/10-artigo-construcao-video-educativosobre-deteccao-precoce-cancer-mama.pdf

22. Silva DF, Santo FHE. O desafio do autocuidado para pacientes oncológicos estomizados. Rev Estima [Internet]. 2014 [citado em 11 jan. 2016];12(2):28-34. Disponível em: https://www. revistaestima.com.br/index.php/estima/article/view/91

23. Sousa CS. Educação pós-operatória: construção e validação de uma tecnologia educativa para pacientes submetidos à cirurgia ortognática [dissertação]. São Paulo: Escola de Enfermagem da Universidade de São Paulo; 2011. 